\title{
Copenhagen 18/12: Africa Must Continue Calling for a Fair, Ambitious and Binding Climate Deal*
}

\author{
Godwell Nhamo, Ph.D.** \\ Exxaro Chair in Business \& Climate Change \\ Institute for Corporate Citizenship, University of South Africa \\ P O Box 392, UNISA, 0003, South Africa \\ Email: nhamog@unisa.ac.za
}

\begin{abstract}
The date, 18 December 2009, left the world perturbed, as global leaders failed to reach consensus on a legally binding climate deal in Copenhagen. Since Bali 2007, much work had been done on preparing for a fair, ambitious and legally binding climate deal. Accordingly, the non-binding Copenhagen (political) Accord was concluded paving the way for further talks in Mexico in 2010. However, the African continent maintained that it had received a raw deal. This paper presents the African Group's climate position and analyses the implications of the Copenhagen Accord for the continent. The paper also presents a way forward for Mexico and beyond. The conclusion urges African governments to hold onto the gains of Copenhagen 2009 and to continue pushing for a fair, ambitious and legally binding climate deal.
\end{abstract}

Keywords

Africa; Copenhagen Accord; Mexico 2010; fair and binding climate deal

\section{Introduction}

In its submission on the outcome of the Ad Hoc Working Group on Long Term Cooperative Action (AWG-LTCA) under the United Nations

* The author thanks Exxaro Resources Limited for sponsoring the Chair in Business and Climate Change run under Unisa's Centre for Corporate Citizenship.

** Godwell Nhamo is a Programme Manager for the Exxaro Chair in Business and Climate Change hosted by the Centre for Corporate Citizenship at Unisa. His interests encompass Business and Climate Change, especially from an African perspective. Some of Godwell research work has been in the broader environmental policy field. His current responsibilities are teaching, research and training in corporate citizenship, sustainability sciences and business and climate change. Godwell has published a number of papers addressing various policy perspectives regarding the Kyoto Protocol regime. 
Framework Convention on Climate Change (UNFCCC), the Africa Group highlighted key issues that were pressing on its agenda. Among such pressing matters was the fact that Africa recognised "the just, fair and equitable right... to achieve development making use of the atmospheric space and resources taking into account the accumulative historical use of such resources by developed country Parties" (African Union, 2009a: 1).

To many, the Copenhagen Accord left Africa on the crossroads as (1) voting 'no' meant creating sour relations and possibly provoking punitive measures from the powerful key players that had crafted the deal, namely the USA, China, India, Brazil and South Africa; and (2) voting 'yes' meant a political commitment to a half-baked deal characterised by a weak architecture that would be unlikely to address the need to reduce carbon emissions to the required-by-science levels of $2^{\circ} \mathrm{C}$, hence a $40 \%$ reduction in 2020 and 80\% in 2050 based on 1990 levels (Oxfam, 2009). The Copenhagen Accord addresses issues ranging from the scientific basis for undertaking greenhouse gas (GHG) emission reductions, obligations for Annex 1 and Non-Annex 1 countries, climate adaptation and mitigation, technology and the establishment of the Copenhagen Green Climate Fund. The Accord presents a serious diplomatic challenge leading up to Mexico City in December 2010 where the UNFCCC Conference to the Parties Sixteenth Session (COP16) will take place.

\section{Methodological Orientation}

This paper is founded on two research questions: (1) What does the Copenhagen Accord imply for Africa and the urgency required to fight climate change? (2) How can the African continent collectively and proactively engage with the Copenhagen Accord and other processes in order to create a fair, equitable and legally binding climate framework post-Kyoto?

This paper makes use of the Actor/Actant Network Theory (AANT) analysis lenses. The author has successfully used this methodological framework in a number of publications dating as far back as 2003 when he looked at environmental policy implementation in South Africa and emerging stakeholder participation paradoxes (Nhamo, 2003), as well as a publication on AANT for tracing actors, actants and their networks in environmental policy formulation and implementation (Nhamo, 2006a). The author's most recent work in applying AANT underpinnings includes a publication on co-leadership in climate change (Nhamo, 2009b) and climate change as a double-edged sword for African trade and development (Nhamo, 2009a). Hence, although there are no formal protocols in qualitative research work like the one under consideration, the author has in a way developed some form of qualitative research 
protocol which uses AANT to investigate contemporary issues in environmental policy in general and climate change in particular.

\section{Theories of International Environmental Policy Formulation}

The manner in which African governments and other developing states' behaviour during the Copenhagen summit may not be fully understood without a discussion on international environmental policy formulation. International environmental policy formulation is informed by a number of theories, among them conservatism, environmental justice, deep ecology, feminism, postmodernism, socialism and liberalism. For the purposes of this paper, environmental justice theory (EJT) will be discussed in depth as this closely explains developments during Copenhagen and possibly events anticipated during COP16. Aspects of human rights and climate ethics are also discussed as part of EJT (Sachs, 2009). EJT draws from Liberal justice Theory (LJT). In LJT, the focus is solely on fair processes for the distribution of goods and benefits (Schlosberg, 2004).

Keohane and Victor (2010) talk of 'regime complex' in climate change. In their view, there is no integrated, holistic regime governing efforts to limit the extent of climate change. Rather, there exists a regime complex characterised by a loosely coupled set of specific regimes. The authors realise that understanding the regime complex helps to explain a situation where most demanding international commitments such as those for addressing climate change are interdependent, yet governments vary greatly in their interests and ability to implement commitments such as those under the UNFCCC and the Kyoto Protocol. Countries construct international regimes based on their national interests that reflect the interests of major constituencies like dominant political and economic structures (Brand, Bullard, Lander \& Mueller, 2009).

The battles during Copenhagen were fought between Annex 1 versus NonAnnex 1 countries. For Africa, the ideology of climate justice emerged strongly. "Climate justice as a concept represents the confluence of different streams of concern with fairness and ethical relations as they relate to people's use of the world's finite carbon resources" (Robinson \& Miller, 2009: 2). Africa still believes countries from the North have contributed and are still contributing much in terms of GHG emissions. To this end it is unfair to expect much from developing countries that are vulnerable to the negative impacts of climate change to which they have contributed the least. Africa, for example, contributes an estimated $3.8 \%$ of the total global GHG emissions.

As outlined in Article 2 of the UNFCCC, the single fundamental challenge of international cooperation for climate governance is how to reconcile the 
objective to reduce and stabilise GHG concentration in the atmosphere with economic growth and international justice (Okereke \& Schroeder, 2009). It is therefore necessary to realise that there is an extreme imbalance in both the distribution and the ability of parties to the UNFCCC to cope with the negative impacts of the changing climate. Climate change then becomes an aspect of (in)justice, as this is the making of the developed North yet it imposes severe risks to the poor who are least responsible and simultaneously most vulnerable to climate change impacts. The language highlighting a need for Copenhagen to reach a fair, ambitious and legally binding climate deal gained popularity from African and other developing countries (Robinson \& Miller, 2009). Climate justice also provides the right platform in terms of evaluating the necessary financial architecture to support just and sustainable climate interventions.

\section{International Climate Policy Formulation}

The UNFCCC is the overarching framework in terms of international climate policy formulation. The UNFCCC came into force in 1994 after receiving over 170 ratification instruments from parties (ICAO, 1998). By design, the UNFCCC is intended to be universal with all parties having an equal say in proceedings (Keohane \& Victor, 2010). The Conference of Parties is the Convention's supreme policy-making institution and has a number of subsidiary bodies and working groups that support the Convention. The scientific basis for taking certain climate policy-related decisions are informed by the Intergovernmental Panel on Climate Change (IPCC). The IPCC brings together about 2,500 reputable interdisciplinary scientists who collate research wok in the field of climate change. The UNFCCC aims at monitoring anthropogenic GHG emissions (UNFCCC, 1992), with arbon dioxide $\left(\mathrm{CO}_{2}\right)$, methane $\left(\mathrm{CH}_{4}\right)$ and nitrous oxide $\left(\mathrm{N}_{2} \mathrm{O}\right)$ being among the chief GHGs. To address the escalating levels of GHGs in the atmosphere, the COPs to the UNFCCC concluded a legally-binding implementation policy instrument called the Kyoto Protocol.

Two fundamental principles built into the UNFCCC that address climate justice are: (1) equity, and (2) the common but differentiated responsibilities of parties (Robinson \& Miller, 2009). The responsibilities of the developed North and the developing South are evident, as these regions have unequal material wealth, social and economic situations, different historical contributions to GHG emissions, as well as different financial and technological capacities. On many occasions during international climate policy formulation, the developing countries, especially those from Africa, have viewed 
proposals from the developed countries with suspicion (Buck, Kollman \& Carius, 2002).

The Kyoto protocol requires developed countries to collectively reduce their GHG emissions by an average of 5.2\% below the 1990 levels between the years 2008 and 2012 (United Nations, 1997; Shin, 1998). The Koyo Protocol was signed in 1997 but only became operational in 2005 following the deposit of the last required ratification instrument by Russia in February of that year. To date, the USA has refused to ratify the Kyoto Protocol, yet it stands out as the second highest global emitter after China. This has caused a great deal of tension between the USA and Africa, as well as the USA and Europe and other regional groupings.

The international climate negotiations follow a two-track system that incorporates what is known as the 'Kyoto track' and the 'Convention track' (Ministry of the Environment, 2009). This is so because other countries like the USA have not ratified the Kyoto Protocol, hence these are covered under the UNFCCC. A summary of the two-track system is shown in Figure 1. The Ad hoc Work Group (AWG) on further commitments for Annex 1 countries coordinates the negotiations within the Kyoto track. This arrangement automatically sidelines even Non-Annex 1 nations that are global players like the Group of Five (G5) emerging nations of Brazil, China, India, Mexico and South Africa. The AWG was established under Article 3 of the Kyoto Protocol (European Parliament, 2008). Under the UNFCCC, an Informal Dialogue on Long-Term Cooperative Action was set-up in July 2005 and ended two years later in August 2007. A new arrangement - the AWG Long-term Cooperative Action - was formed under the UNFCCC, which keeps the two tracks separated. The two groups' work was expected to converge leading to a post-Kyoto Protocol framework in Copenhagen.

Taking cognisance of the fact that climate change is a global challenge and that emission reductions are necessary regardless of their spatial location, the Kyoto Protocol establishes three distinctive flexible mechanisms to reduce GHG emissions (Brunnengraber, 2009). These carbon trade mechanisms, which all result in credits being earned by the investing country, include (1) The Joint Implementation (JI) mechanism (Article 6), which earns the investing country emission reduction units (ERUs); (2) the CDM (Article 12), which earns the investing country certified emission reductions (CERs); and (3) the Emissions Trading (ET) mechanism (Article 17), which earns the investing country assigned amount units (AAUs). Given that developing (host) countries cannot engage the JI and ET mechanisms and for the purposes of this paper, the following section will briefly elaborate on the CDM. 


\section{Figure 1}

Climate negotiating tracks

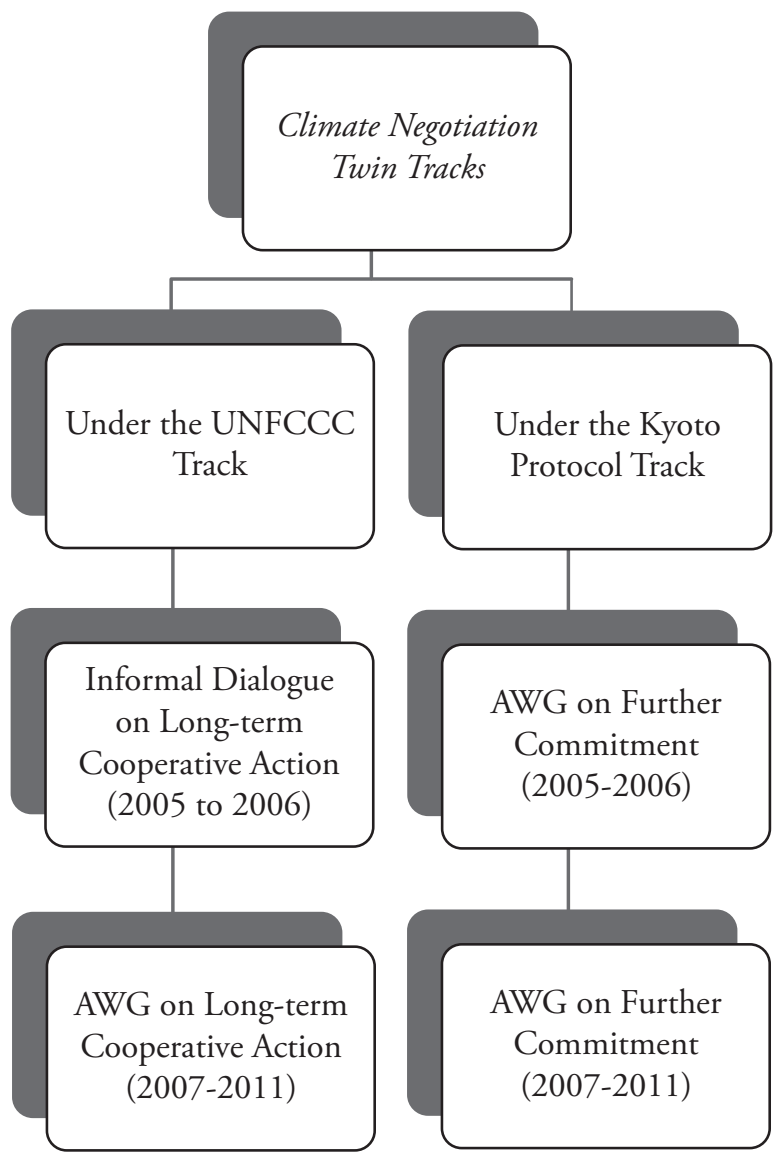

Source: Author (based on European Parliament, 2008: 2)

As indicated earlier, the climate negotiation environment is dynamic, volatile and, at times, explosive. This was witnessed before and during the Copenhagen talks that saw the developing countries walk out twice (once in Barcelona in November 2009 and once in Copenhagen). The developing countries argue that, for a long time, they have been left on the margins of climate policy negotiations and at times excluded in some informal rounds of talks where 'things' happen. The main reason for the walkouts was that developing and poorer nations wanted to see decisions that would lead to 
a 40\% drop in greenhouse gas (GHG) emissions by 2020 based on 1990 levels (Otton, 2009).

The climate negotiating space cannot be fully understood without reference to the Bonn and Bali Roadmap. Adaptation was high on the Bonn agenda (Climate Action Network, 2008); industrialised countries for example, had for decades enjoyed high levels of energy consumption (the main source of GHG) through which they accumulated substantial economic, institutional and technological wealth and consequently higher potential for gains from and better capacity to invest in the more expensive mitigation response options. It is also true that most of the regions that are predicted to benefit from global warming fall in the industrialised North (Hassan, 2008).

The Bali Conference is cited as one of the key landmarks of Copenhagen 2009. The Bali Conference managed to effectively launch negotiations to craft a new international climate change agreement by the end of 2009. It spelt out a clear roadmap for these talks (Africa Union, 2007). Some of the notable immediate results, which were particularly important for developing countries, not least in the areas of adaptation funding, technology transfer and reducing emissions from deforestation. The Bali Conference also established a roadmap for negotiations on the new emission targets for industrialised countries under the Kyoto Protocol, along with defining the scope and content of the upcoming review of the Protocol.

In the UNFCCC process, in theory, each country holds an equal vote (Shanahan, 2007). However, in reality, there is a big difference in the negotiating power of individual nations. Some have teams of well-trained negotiators, whereas others have individuals who may be meteorologists or technicians without training in negotiating. The developed and rich countries have used this to their advantage in the past by negotiating at length on minor issues, leaving opponents tired out, and then rapidly bringing in key decisions. In addition to country delegations, nations come together in different blocks to negotiate on common interests. Details of the negotiating groups are presented in Figure 2. Although most of their members are also part of the G77+China, the least developed countries (LDCs) and the Association of Small Island States (AOSIS) want large developing nations such as China and India to reduce their emissions. This break from solidarity within the larger block is a new development (Shanahan, 2007).

The Africa Group comprises 50 countries that are seeking to highlight their particular vulnerability to climate change and other issues of concern, such as poverty and access to resources and justice. The AOSIS is a coalition of 43 small islands and low-lying coastal countries that share similar development challenges and concerns about the environment, especially their vulnerability 
Figure 2

Negotiating groups for COP 15

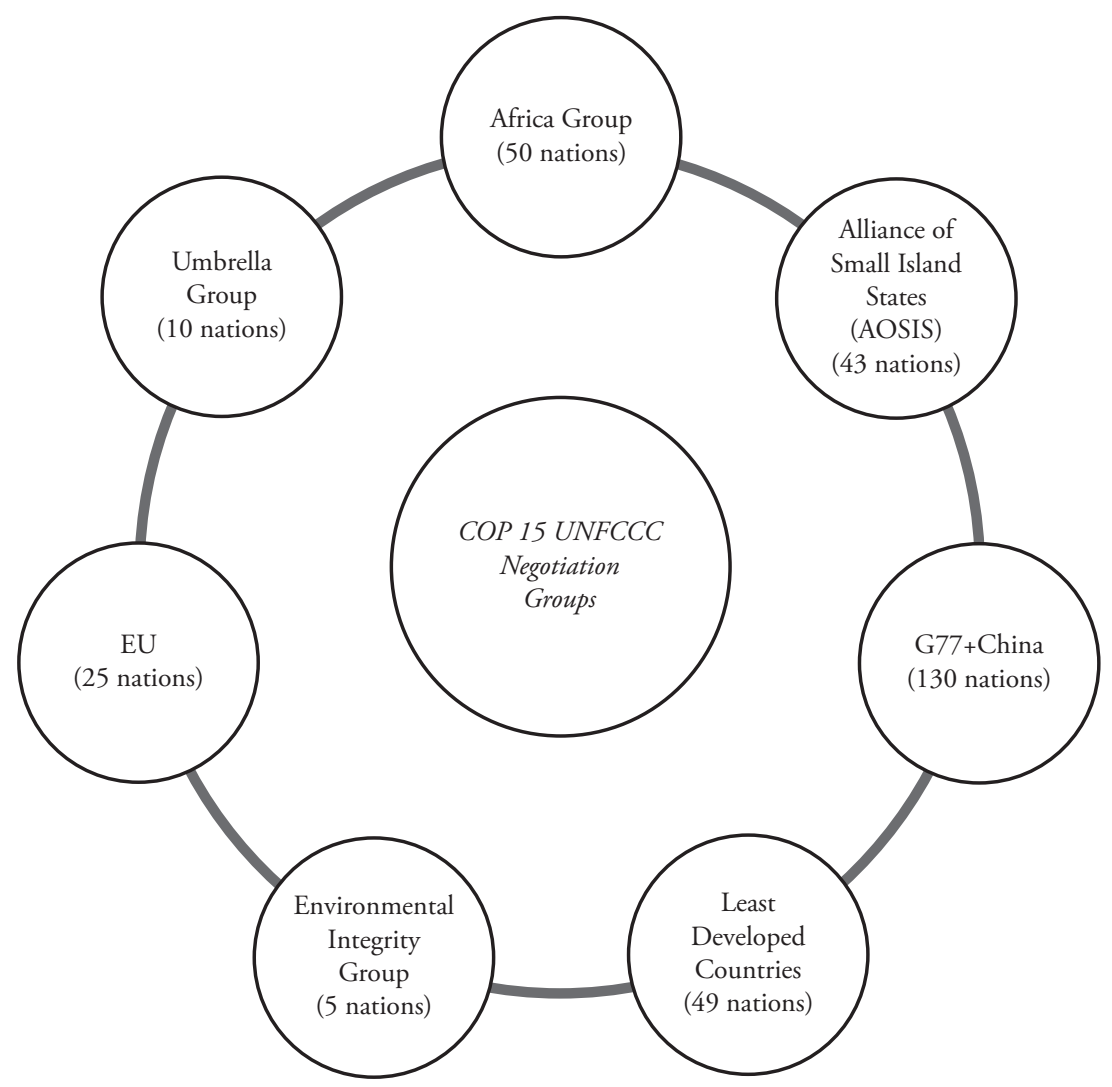

Source: Author (figures drawn from IIED, 2009)

to the adverse effects of global climate change, including sea-level rise. The Environmental Integrity Group (Mexico, South Korea and Switzerland, together with Liechtenstein and Monaco) sometimes intervene as a separate negotiating group to ensure their inclusion in last-minute, closed-door negotiations. The European Union (EU), which comprises 27 member states, negotiates as a unified entity and the Umbrella Group brings together non-EU Western nations (Australia, Canada, Iceland, Japan, New Zealand, Norway, Russia, Ukraine and the US). The G77+China brings together 130 countries whose main position is that the rich countries should accept their historical responsibility for climate change and greatly reduce their emissions 
while allowing the G77+China to continue to develop. Within that group there are some tensions owing to the wide diversity among countries and regions. Within the G77+China there are a number of regional and specialinterest subgroups. The 49 LDCs are the world's poorest countries and are mostly in Africa. Their emissions are tiny compared to those of other countries and they are the least prepared for the changes ahead. The 13-member Organization of the Petroleum Exporting Countries (OPEC) is not a formal negotiating group, but often creates barriers to progress in the negotiations because oil is a major source of greenhouse gases and the lifeblood of their economies.

\section{Africa and Climate Negotiations}

Africa's climate negotiation environment cannot be fully understood without taking stock of both formal and informal negotiating arrangements. The continent is split in the formal and informal set-up to the level where speaking with one strong climate voice becomes very difficult (Figure 3). Under the UNFCCC, four formal negotiation groupings to which African countries are affiliated include the Africa Group, the Alliance of Small Island States (AOSIS), the Least Developed Countries (LDCs) and G77+China. The formal climate negotiations are undertaken on the basis of the two-track system that considers proposals from the two AWGs from the UNFCCC and the Kyoto Protocol. This makes it possible for all countries to be covered since some such as the USA have not ratified the Kyoto Protocol.

However, it is the informal negotiating groups that make life difficult for the African continent as speaking with one united climate voice can be complicated. This is because informal groups are smaller and coherent; their strong associations and the need to be dominant forces in either wrestling climate change leadership or maintaining a stronghold in climate leadership facilitates their sticking together. Such informal groups have hidden agendas that are usually felt and seen from their negotiating positions or lack of in formal groups. Some of the more noticeable informal climate negotiation groupings affecting Africa are the Major Economies Forum, the G20 and a host of smaller blocks linked to the continent's largest GHG emitter, South Africa. These small blocks include Basic/Brics (Brazil, South Africa, India and China), G8+5 (G13) as well as Basic + the USA. The Basic + USA group is the newest having emerged during Copenhagen 2009. The Basic protects its interests by taking advantage of belonging to Non-Annex 1 countries yet leveraging its role as an emerging global economic and military powerhouse. Basic sees further cooperation both within its boundaries and with global superpowers as 
Figure 3

Africa's climate negotiation surrounds

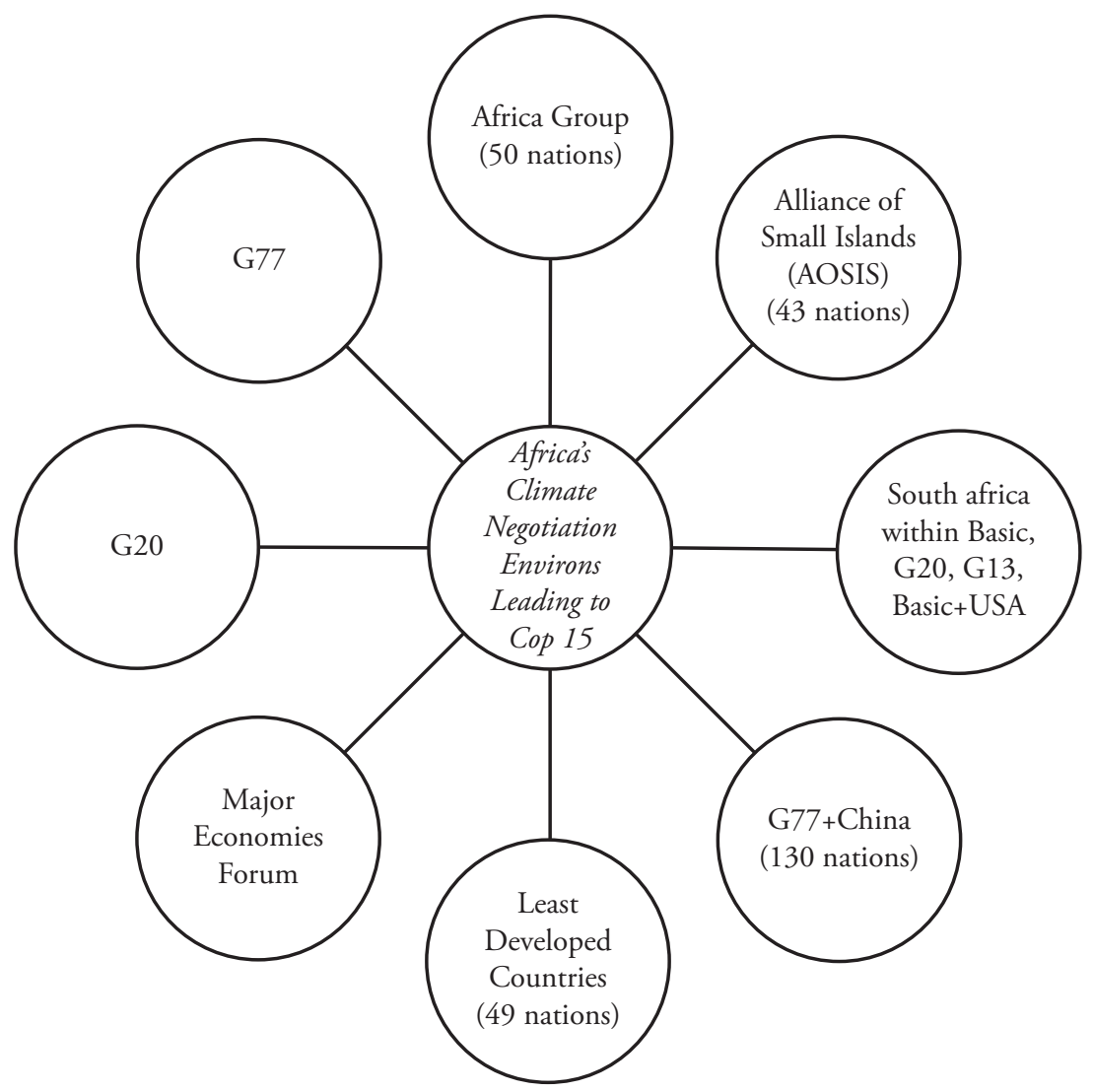

Source: The Author

an opportunity to propel its economic and industrial growth. As a member of Basic and other global groupings like the G8 and G20, South Africa usually finds itself excluded by the Africa Group during climate negotiations.

\section{Africa During Copenhagen 2009}

At the 10th African Union Summit held in 2008, the Executive Council expressed concern regarding the seriousness of climate change, highlighting the importance of tackling the challenges of climate change in the international 
arena and the particular threat it poses to Africa (AMCE, 2008). The Council welcomed the Tunis Declaration and Action Plan on International Solidarity against Climate Change in Africa and the Mediterranean region. The Declaration states that climate adaptation should be integrated within sustainable development policies, strategies and plans with a view to achieving sustainable economic growth and eradicating poverty.

During Copenhagen 2009, negotiation groups and national positions were heard on 16 and 17 December 2009. Such statements were made during the high-level segment by heads of state, heads of government or heads of delegations. The G77+China emphasised a need to maintain the two-track outcome under the UNFCCC and the Kyoto Protocol (IISD, 2009). The Group also encouraged agreement on the establishment of a second commitment period under the Kyoto Protocol. The African Group reiterated the importance of the continent:

Speaking with one voice, and outlined a short-term finance proposal that includes: US $\$ 10$ billion per year for 2010-2012; a board of trustees with representatives from an equal number of donor and recipient countries; $40 \%$ of funds earmarked for Africa; and a committee of experts to facilitate the launch of the fund. On long-term financing he said, inter alia, that US $\$ 100$ billion per year by 2020 would be required with at least $50 \%$ earmarked for the LDCs and SIDS, and that Africa's share should be administered by the African Development Bank (IISD, 2009: 3; African Union, 2009b: 3-4).

The foregoing citation confirms that African countries had a well-documented position for Copenhagen 2009. Any other negotiating positions from Africa were then assumed to support the Africa Group's position. In its submission to the AWG-LTCA, the African Union (2009a) indicated its wish to have a shared vision on long-term cooperative action. Such a vision would see parties to the UNFCCC working on the basis of common but differentiated responsibilities and respective capabilities. The African Union also expected action to be taken in an equitable manner taking historical responsibility into account. This proposal meant that Africa would not do as much as Annex 1 countries, although it would do its bit in terms of voluntary nationally appropriate mitigation actions (NAMAs). These NAMAs would include appropriate measures to reduce GHG emissions through a number of measures that include increased forestry cover, stabilised forest carbon stocks and enhanced carbon sinks.

Africa noted that a number of issues previously deliberated on under the UNFCCC and its Kyoto Protocol framework had not been fulfilled. To this end, the African Union expected a Copenhagen deal that would fulfil, among 
other aspects, the provision of adequate funding for adaptation to the tune of not less than $2.5 \%$ of developed countries' gross domestic product annually, technology development and transfer, capacity building and committing to a legally binding second Kyoto Protocol phase (African Union, 2009a: 3-4). With regard to mitigation commitment by Annex 1 countries, Africa expected Copenhagen to witness a GHG emission reduction pledge of at least $45 \%$ based on 1990 levels by 2020 (African Union, 2009a). For those Annex 1 countries that had not previously committed significant emission reductions targets, Africa expected at least a $45 \%$ GHG emissions reduction target by 2020 and at least $95 \%$ by 2050 based on 1990 levels.

Further insights from the Africa Group into what transpired during the Copenhagen talks became clearer with minutes published by the Canadabased International Institute for Sustainable Development (IISD). According to the IISD, Egypt was one of the countries together with Bangladesh, Tuvalu and Guatemala that complained that well into the Copenhagen talks the COP President had not approached the countries for consultation. This group of countries expressed their fear in terms of the secrecy surrounding the negotiations and indicated that they wished Copenhagen could have been "inclusive, transparent and include[d] all major groups" (IISD, 2009: 4). Nigeria, in a group of other non-African countries that included Argentina, Venezuela and Pakistan, also encouraged "openness, transparency and inclusiveness in the consultations, lamenting the lack of transparency" even as Copenhagen talks were in their last day. Angola joined Venezuela and "drew attention to the option of not taking any decision on market approaches". This was a view strongly supported by the USA as it did during Kyoto in 1997 (Nhamo, 2006).

In the end, Basic + USA drew up the Copenhagen Accord excluding the EU. The document was further discussed by 25 heads of state. The Copenhagen Accord was presented to other countries present "giving them one hour to read and sign on" (Oxfam, 2009: 6). The EU reluctantly accepted the Copenhagen Accord although many developing countries including those from Africa refused to endorse it. As such, COP15 'noted' as opposed to 'adopting' the Copenhagen Accord (Black, 2009). Reacting to the Copenhagen Accord, Sudan condemned it:

Stressing that it threatens the lives and livelihoods of millions of people in developing countries, including the African continent. He referred to the financial commitment of US $\$ 100$ billion in the document as 'a bribe', saying that a commitment to $2^{\circ} \mathrm{C}$ would ask Africa to 'sign an incineration pact' and was based on values that 'tunnelled six million people in Europe into furnaces (Black, 2009). 
After significant discussions, protests and contestations, COP Vice-President Philip Weech (Bahamas) proposed that COP adopt a decision that takes note of the Copenhagen Accord of 18 December 2009 (IISD, 2009). The decision text was finally read out indicating that the Accord would be attached to the decision and names of parties that support it would be listed. Senegal supported clarity on accession to the Copenhagen Accord, adding that if a country rejects the Copenhagen Accord, it should not have access to the proposed Copenhagen Green Climate Fund. It is statements like these that bring division in terms of the Africa Group and some countries. In this case Senegal will be viewed favourably and, as discussed earlier, Sudan might be viewed otherwise.

\section{Copenhagen Accord and Its Implications for Africa}

Although the continent significantly influenced agreement on and the establishment of the Copenhagen Green Climate Fund as enshrined in the Copenhagen Accord, more could have been salvaged had the continent spoken with a true single climate voice. South Africa entered into an arrangement that witnessed the birth of the Copenhagen Accord. The small group that crafted the Copenhagen Accord architecture included the USA, China, Brazil, South Africa and India. The Copenhagen Accord is presented in 12 bullets, which will now be discussed in depth.

Points to note for Africa in terms of the First Bullet include the phrase: "We emphasise our strong political will to urgently combat climate change in accordance with the principle of common but differentiated responsibilities and respective capabilities" (UNFCCC, 2009: 1). The Africa Group battled to keep this principle from the UNFCCC, as powerful nations, among them the USA, Australia and others, wanted major economies to take GHG emission reduction targets. The ultimate was that South Africa surprised many by pledging to reduce its GHG emissions (Zuma, 2009). The idea of "equity and in the context of sustainable development" was left vague and Africa needs to pursue this with much rigour in 2010 and beyond. The use of per capita GHG emissions is one that could truly reflect equity in the climate negotiation space. The first bullet also highlights that the Accord stresses "the need to establish a comprehensive adaptation programme including international support" (UNFCCC, 2009: 1). Two key points emerge here: a need to put in place a functional adaptation programme; and the establishment of a supporting international framework. Both issues would require Africa to be proactive in putting in place the necessary supporting infrastructure 
and systems and to make sure that the so-called international support is not selective and vindictive towards African countries that were most vocal during Copenhagen 2009.

The second bullet fails to explicitly state that GHG emission from Annex 1 countries has already peaked as is recognised by the Kyoto Protocol. Instead it talks of a longer peaking in developing countries including those from Africa and uses the phrase "as soon as possible". For a continent that must be climate compliant like Africa, one then asks, how soon is "as soon as possible"? Instead, another layer of expectation from Africa is enshrined in bullet two - a need to come up with low-emission development strategies. This might imply that African countries that do not present such strategies could be excluded from international support, be it technical, financial or otherwise.

Bullet three brings back an old promise of financial support for climate adaptation in Africa. The Accord records thus: "We agree that developed countries shall provide adequate, predictable and sustainable financial resources, technology and capacity-building to support the implementation of adaptation action in developing countries" (UNFCCC, 2009: 2). The aspects of intellectual property rights and patents are as old as humankind and technology transfer from the developed world has been jealously guarded in terms of its deployment to Africa. Technological advancement is always seen as tilting the gradient in favour of the 'haves' rather than the 'have-nots' like Africa. Even under the Kyoto Protocol technological development was included and very little was achieved on this front. Africa therefore must put in place a strong monitoring and verification programme in terms of technology development and deployment.

The main pointer from bullet four is the self-regulation of GHG emissions in terms of Annex I Parties that are not party to the Kyoto Protocol. Such selfregulation is not good enough and results in sickly commitments like those presented by the USA pre-Copenhagen. Such pledges will certainly leave Africa under sustained pressure from the impacts of increasing GHG emissions. Self-regulation could also be opted for by current Annex 1 parties under the Kyoto Protocol framework once it lapses in 2012. The EU, for example, has pledged a 20\% GHG emission reduction by 2020 that could have been increased to $30 \%$ by the same time had other Annex 1 countries been forthcoming (International Centre for Climate Governance, 2009).

Logical as it might appear, bullet five brings back the scramble and partitioning of the African continent. The bullet starts by indicating that "Non-Annex I Parties to the Convention will implement mitigation actions.... Least developed countries and Small Island Developing States may undertake actions voluntarily and on the basis of support". Although the three groups of 
countries are based on the formally recognised negotiation groups from the UNFCCC, Africa finds itself in three groups that can be divided and ruled on the basis of their engagements with the climate mitigation space. Countries like Nigeria and Sudan that have expressed reservations in the manner in which Africa engages the climate space could be targeted. Another pointer from bullet five is the "domestic measurement, reporting and verification the result of which will be reported through their national communications every two years" (UNFCCC, 2009: 2). The measurement, reporting and verification (MRV) aspects became a thorny issue during Copenhagen as this was raised by Hillary Clinton after she pledged USA support to mobilise support in raising US $\$ 100$ billion annually to fight climate change in developing countries including Africa (Goldenberg, Vidal \& Watts, 2009). China and India strongly opposed the fundamentals surrounding the MRV saying this had the potential to violate their sovereignty (Andersen, 2009). The USA, however, maintained that this was a transparency, rather than a sovereignty, issue.

The controversial aspect regarding African and other forests in reducing GHGs from the atmosphere through carbon sinks was addressed under bullet five. A number of African countries have vast forest resources that must be used as a strong bargaining chip in climate negotiations. However, debates have been centred around how to measure the impacts such forests have on reducing GHG emissions and Africa has lost valuable leverage in terms of the years it has taken to come to some form of consensus on this aspect. Given that REDD is now on the post-Kyoto Protocol framework radar, African governments need to move swiftly to determine conditions in terms of which the funds mobilised for REDD-plus are utilised. Once more, the idea here will be to guard against divide-and-rule tactics expected from developed countries. It would be best if such funds were to be administered by the African Union rather than become bilateral through formal UNFCCC channels (African Union, 2009b).

The current Kyoto Protocol architecture is market based (Ministry of the Environment, 2009). This has resulted in the CDM project being dominated by China, Brazil, India and South Africa (Nhamo, 2006b). Many African countries with small GHG emissions are yet to recognise the benefits associated with CDM, yet bullet seven from the Copenhagen Accord emphasises the continuation of the use of markets "to enhance the cost-effectiveness of, and to promote mitigation actions" (UNFCCC, 2009: 2-3). To cover-up for the deficit in terms of CDM project flow into many African and other developing countries, the Accord promises low-emitting economies from developing countries unspecified incentives so that they can continue to do so a low-emission pathway. The fact that there is a need to regulate markets cannot 
be overemphasised as the world learnt its lessons from the 2008/9 financial meltdown (Kolk \& Pinkse, 2009).

Bullet eight revisits the proposal for "scaled up, new and additional, predictable and adequate funding as well as improved access" to be provided to developing countries (UNFCCC, 2009: 3). Such funding is designated for enhanced action on mitigation that would include substantial finance to reduce GHG emissions from REDD-plus, adaptation, technology development and transfer as well as capacity-building. In terms of figures, US\$30 billion was stipulated for the period 2010-2012 and this would be shared equally between adaptation and mitigation. Further financial commitment was pledged but with strings attached, that is, on the condition that "meaningful mitigation actions and transparency on implementation, developed countries commit to a goal of mobilizing jointly US $\$ 100$ billion dollars a year by 2020 to address the needs of developing countries" (UNFCCC, 2009: 3). The Accord also stipulates that a significant share of such funding be handled through the Copenhagen Green Climate Fund. If the funds can be raised, this will be a welcome initiative for Africa. As it stands, the EU has pledged to see this come to fruition.

Bullets nine and ten elaborate on the fundraising mechanisms and the creation of the Copenhagen Green Climate Fund. Bullet nine identifies a high-level panel that will be formed to "study the contribution of the potential sources of revenue, including alternative sources of finance, towards meeting this goal" and bullet ten establishes the Copenhagen Green Climate Fund (UNFCCC, 2009: 3). What is of importance for Africa is to be fairly represented on both the high-level panel and the institution that will govern the Copenhagen Green Climate Fund. Up to now, Africa has been sidelined in major international finance bodies like the World Bank and the International Monetary Fund.

Since the issue of technology has always been dodgy, this is the sole concern of bullet 11 . What needs to be noted is the fact that statements from bullet 1 , such as "that will be guided by a country-driven approach", as well as "be based on national circumstances and priorities", are open ended and subject to (mis)interpretation. For example, an African country that is severely affected by climate change but does not have a country-driven approach will miss out on the technological mechanism. Similarly, a country that might not prioritise climate change due to the fact that it might be chasing another nationally acceptable agenda like land reform might also miss out. Hence, an element of attaching strings to coerce a response from Africa is still prevalent in international regulatory regimes (Nhamo, 2009a). Africa is still silently treated as a lesser partner. 
The last bullet stipulates that the Copenhagen Accord will end in 2015 (UNFCCC, 2009) and calls for an assessment of the implementation of the Accord. Already, a number of African and other countries (both from the developed and developing worlds) have refused to sign the Accord and its implementation will be compromised owing to the manner in which negotiations took place and the arm-twisting that happened thereafter from the USA + Basic.

\section{Policy Perspectives Moving Forward}

The problems of multiple voices and, more specifically, divergent climate voices from Africa are still significant. This is so because the Africa Group is the most dissected, with countries parcelled out to both formal and informal climate negotiating groups as highlighted earlier. Given this puzzle, it becomes almost impossible for the Africa Group to speak with a single, united climate voice. Since global warming and climate change is a matter of life and death for the continent, it is important that policy pointers be presented to serve as a platform for working on moving forward.

Building on Copenhagen Accord gains: The most significant achievement from Copenhagen for Africa was the establishment of the Copenhagen Green Climate Fund. Although the US $\$ 400$ billion tag Africa wished for could not be met, the US $\$ 100$ billion annual pledge by 2020 to the Fund is significant. African countries with access to this proposed fund must be proactive and meet the pre-conditions for accessing the funds.

Keeping negotiations within the UNFCCC framework: An alternative leaked Danish presidency negotiation text (Oxfam, 2009) created havoc in Copenhagen and a blanket of mistrust emerged. The document seemingly favoured Annex 1 countries and contained a proposal that sought to replace the twotrack approach with a single new agreement. Although the proceedings finally got back on track to focus on official texts, negotiating time had been lost. In Mexico 2010, Africa must be on the lookout for such sidetracking in order to maximise negotiation time. The Africa Group must also continue lobbying for the reformation of the United Nations system of governance. Although this has been on the agenda for a long time, the need to reform the United Nations system was once again highlighted by Ed Miliband of the UK (Miliband, 2009) following the shame in Copenhagen 2009.

Speaking with one, united climate voice: Africa must continue speaking with one, united voice leading up to and during Mexico 2010. Having African countries represented in multiple formal negotiating bodies like the LDC, the AOSIS, the G77+China and the Africa Group could have been a long-term 
ploy by the developed world to continue dividing and ruling the continent. A roadmap to speaking with one, united climate voice must be crafted within the broader cooperation arrangement for the continent.

Technical and negotiation expertise: Oxfam (2009: 5) notes how outnumbered and thinly spread Africa's negotiating teams were during Copenhagen 2009. Rich and emerging nations like Brazil, China and India were reported to have been represented by legions of men and women:

To do politics and business: Canada sent 183, Japan 134, the US 194 - Brazil 750, India 52, and China 233. Poor countries, most under threat from climate impacts, had small delegations - Chad 10, Haiti 7, and Dominica 4 - who could not possibly cover all the parallel talks and ever-changing texts. Rich countries applied pressure down the phone lines too: Australia, for example, leaned on Tuvalu and other Pacific islands to stop calling for a goal of keeping global temperature rise below $1.5^{\circ} \mathrm{C}$.

Such differences in human resources and business sensitivity need to be checked come Mexico 2010.

Leveraging from other sources of power: Although Africa might not have huge political muscle, the continent is endowed with natural resources that can be used as leverage for a fair climate deal in the future. The diamond, gold, platinum, coal and forests are all potential sources of economic muscle (Nhamo, 2009a). The days when the developed nations control the continent's resources must be brought to an end.

Climate ethics, fairness and compensation: No one can dispute the fact that Africa did not significantly contribute to the current climate change problem. It is right that those that polluted and continues to do so most should pay. The point here is that Africa must continue fighting for climate compensation and have it on the global agenda for the generations to come that might understand the dynamics. At the same time, the fundamentals surrounding common but differentiated responsibilities in terms of addressing climate change should not be violated as almost happened at Copenhagen 2009.

Climate change technology: Cannady (2009) presents useful insights into the subject of climate technology. She argues for a practical two-pronged strategy that considers: (1) a climate change technology innovation strategy that looks at supporting climate change research and innovation in developing countries by developing country scientists, and (2) 'win-win' development collaboration agreements for climate change technology between developed and developing country parties. In her proposal, the first prong must be the foundation that makes the second one feasible. African governments should take note of the two approaches proposed here in the lead-up to 2013. 
Clarity on South Africa's roles: The roles of South Africa when negotiating for a climate deal are complex, as these have changed from one situation to another bearing in mind that any country would wish for a deal that suits its developmental needs. As a significant GHG emitter it is only fair to let South Africa break away and negotiate separately from the African Group. Like China, South Africa could be called upon for leverage but without pinning hopes on it. Hence, the Basic Group might be its rightful place although this group is not a formal UNFCCC negotiating platform. This might also minimise tensions within the Africa Group as were experienced during Accra in 2008 and Copenhagen 2009.

\section{Conclusion}

This paper deliberated on the events that took place during the Copenhagen Climate Summit in December 2009. The focus was on how the Africa climate negotiation group engaged with the proceedings that led to the conclusion of the Copenhagen Accord. The behaviour of the Africa Group was explained in details in terms of Environmental Justice Theory. Given the fact that NonAnnex 1 countries have contributed the least to GHG emissions and yet they are the most vulnerable, the African countries felt Copenhagen gave them an unjust deal. The paper then proposed that the Africa Group should present a united front leading up to and during climate negotiations in Mexico 2010. Some of the policy perspectives presented for the Africa Group included the need to keep climate negotiations within the UNFCCC and Kyoto Protocol framework (the so-called two-tract system) and leaving South Africa with a loose role as the country finds itself in a difficult negotiating position. Overall, the paper calls on Africa to continue pressing for a fair, ambitious and binding climate deal in Mexico and beyond.

\section{References}

Africa Union. 2007. 'Climate change: African perspectives for a post-2012 agreement', Addis Ababa: AU Secretariat.

African Union. 2009a. 'The Copenhagen decisions: Submission on the outcome of the Ad Hoc Working Group on Long Term Cooperative Action under the Convention under item 3', Addis Ababa: Africa Union Secretariat.

— . 2009b. 'Statement by H.E. Meles Zenaoui Prime Minister of Federal Democratic Republic of Ethiopia on behalf of the African Group, Copenhagen, Denmark December 16, 2009', Addis Ababa: Africa Union Secretariat. 
AMCE (African Ministerial Conference on the Environment). 2008. 'Climate Change Adaptation in Africa', Johannesburg: African Ministerial Conference on the Environment.

Andersen, M. 2009. 'China and India signal progress on transparency'. COP15 [On-line]. Available: http://en.cop15.dk/news/view+news?newsid=3048 (accessed 18 December 2009).

Black, R. 2009. 'Copenhagen climate deal meets qualified UN welcome', BBC News [On-line]. Available: http://news.bbc.co.uk/2/hi/science/nature/8422133.stm (accessed 21 December 2009).

Brand, U., Bullard, N., Lander, E. and Mueller, T. 2009. 'Radical climate change politics in Copenhagen and beyond: From criticisms to action?', Critical Currents, 6, 9-16.

Brunnengraber, A. 2009. 'Kyoto's "flexible mechanisms" and the right to pollute the airs', Critical Currents, 6, 26-36.

Buck, M., Kollman, K. and Carius, A. 2002. International Environmental Policymaking and Transatlantic Cooperation: Setting the Agenda for Rio + 10', Berlin: Ecological Centre for International and European Environmental Research.

Cannady, C. 2009. 'Access to Climate Change Technology by Developing Countries: A Practical Strategy', International Centre for Trade and Sustainable Development: Geneva.

Climate Action Network. 2008. 'Adaptation Olympics: Gold Medal awaits!', Accra, CAN.

European Parliament. 2008. 'State of play of post-Bali negotiations', Brussels: European Parliament Secretariat.

Goldenberg, S., Vidal, J. and Watts, J. 2009. 'Victory for developing nations as rich countries abandon effort to kill off Kyoto', Guardian [On-line]. Available: http://www.guardian.co.uk/ environment/2009/dec/17/developing-nations-kyoto (accessed 17 December 2009).

Hassan, R. 2008. 'Coping with and adapting to climate change: Effective mechanisms and policy challenges for agriculture in Sub-Saharan', Africa Nairobi: AERC.

ICAO (International Civil Aviation Organization). 1998. 'Developments in other United Nations Environmental Policy-Making Bodies with an Interest in Civil aviation', New York: International Civil Aviation Organization.

IIED (International Institute for Environment and Development). 2009. 'COP15 for journalists: a guide to the UN climate change summit', London: International Institute for Environment and Development.

IISD (International Institute for Sustainable Development). 2009. 'Summary of the Copenhagen climate change conference: 7-19 December 2009', Toronto: International Institute for Sustainable Development.

International Centre for Climate Governance. 2009. 'EU environment ministers offer "coleadership" on climate', Climate Policy News, 1-2.

Keohane, R. O. and Victor, D. V. 2010. 'The Regime Complex for Climate Change', Oxford: Institute for International Law and Justice.

Kolk, A. and Pinkse, J. 2009. 'Business and climate change: Key challenges in the face of policy uncertainty and economic recession'. Management Online Review, 1-9.

Miliband, E. 2009. 'The road from Copenhagen', Guardian [On-line]. Available: http:// www.guardian.co.uk/commentisfree/2009/dec/20/copenhagen-climate-change-accord (accessed 26 December 2009).

Ministry of the Environment. 2009. 'Negotiations on a new international climate agreement', Copenhagen: Ministry of the Environment.

Nhamo, G. 2003. 'South Africa's waste management policy implementation: Emerging stakeholder participation paradoxes', Southern African Journal of Environmental Education, 20, $37-50$.

- 2006a. 'Actor/Actant-Network Theory as emerging methodology for environmental education in Southern Africa', Southern African Journal of Environmental Education, 23, 34-47. 
2006b. 'Institutional and legal provisions for the Clean Development Mechanism in South Africa', In K.Aravossis, C. A. Brebbia, E. Kakaras, \& A. G. Kungolos (Eds.), Environmental Economics and Investment Assessment, (pp. 167-176). Southampton: Witpress.

— . 2009a. 'Climate Change: Double Edged Sword for African Trade and Development', International Journal of African Renaissance, 4, 117-139.

— . 2009b. 'Co-leadership in climate change: An agenda for 2013 and beyond', Politikon: South African Journal of Political Studies, 36, 463-480.

Okereke, C. and Schroeder, H. 2009. 'How can justice, development and climate change mitigation be reconciled for developing countries in a post-Kyoto settlement?', Climate and Development, 1, 10-15.

Otton, C. 2009. 'World leaders try to save floundering climate summit' Mail\&Guardian [On-line]. Available: http://www.mg.co.za/article/2009-12-15-world-leaders-try-to-save-floundering-climatesummit (accessed 15 December 2009).

Oxfam. 2009. 'Climate shame: get back to the table: Initial analysis of the Copenhagen climate talks', London: Oxfam.

Robinson, M. and Miller, A. M. 2009. 'Expanding Global Cooperation on Climate Justice', London: Brettonwoods Project.

Sachs, W. 2009. 'Climate change and human rights', Critical Currents, 6, 85-91.

Schlosberg, D. 2004. 'Reconceiving Environmental Justice: Global Movements and Political Theories', Environmental Politics, 13, 517-540.

Shanahan, M. 2007. 'A journalist's guide to the Bali climate conference', London: International Institute for Environment and Development.

Shin, S. 1998. 'Developing country's perspective on COP3 development (Kyoto Protocol)', Energy Policy, 26, 519-526.

UNFCCC (United Nations Framework Convention on Climate Change). 1992. 'United Nations Framework Convention on Climate Change', New York: United Nations Framework Convention on Climate Change Secretariat.

—. 2009. 'Copenhagen Accord', Copenhagen: United Nations Framework Convention on Climate Change.

United Nations. 1997 'Kyoto Protocol to the United Nations Framework Convention on Climate Change', Kyoto: United Nation Secretariat.

Zuma, J. 2009. 'Message by South African President Jacob Zuma to the UN Secretary General's High Level Summit on Climate Change', Pretoria: The Presidency. 